\title{
Solitary mediastinal lymph node metastasis in rectosigmoid carcinoma: a case report
}

\author{
Khaled M Musallam¹, Ali T Taher ${ }^{1}$, Ayman N Tawil2, Zaher I Chakhachiro², \\ Moh'd Z Habbal² and Ali I Shamseddine*1
}

\author{
Address: ${ }^{1}$ Department of Internal Medicine, Hematology-Oncology Division, American University of Beirut Medical Center, Beirut, Lebanon and \\ 2Department of Pathology and Laboratory Medicine, American University of Beirut Medical Center, Beirut, Lebanon \\ Email: Khaled M Musallam - kmm06@aub.edu.lb; Ali T Taher - ataher@aub.edu.lb; Ayman N Tawil - at04@aub.edu.lb; \\ Zaher I Chakhachiro - z_shak@hotmail.com; Moh'd Z Habbal - mh03@aub.edu.lb; Ali I Shamseddine* - as04@aub.edu.lb \\ * Corresponding author
}

Published: 31 July 2008

Cases Journal 2008, 1:69 doi:10.1186/1757-1626-1-69

This article is available from: http://www.casesjournal.com/content///I/69

(c) 2008 Musallam et al; licensee BioMed Central Ltd.

This is an Open Access article distributed under the terms of the Creative Commons Attribution License (http://creativecommons.org/licenses/by/2.0), which permits unrestricted use, distribution, and reproduction in any medium, provided the original work is properly cited.
Received: 6 July 2008

Accepted: 31 July 2008

\begin{abstract}
Introduction: Colorectal cancer most commonly metastasizes to the regional lymph nodes, liver, bone, lung, and brain. Metastases to mediastinal lymph nodes is a rare entity which has never been reported to be solitary.

Case report: We herein describe a 67-year-old male patient with a solitary mediastinal lymph node metastasis three years following the resection of his primary rectosigmoid carcinoma. Pathological characteristics of the metastatic tissue and technical limitations in imaging modalities resulted in incongruity between follow-up CT and PET scans. Diagnosis of this distant metastasis has been confirmed through a mediastinoscopic biopsy.

Conclusion: Attention should be paid to the mediastinum when evaluating PET scan or CT films during follow-up of patients with colorectal cancer. Using PET/CT instead of separate morphological and functional data sets favors better detection. Questions still remain concerning the ideal management protocol of such a presentation, the two main options being locoregional or chemotherapeutic.
\end{abstract}

\section{Introduction}

Colorectal cancer is the third most common cancer as well as the third most common cause of cancer death in both men and women [1]. Rectosigmoid colon continues to be the most common site while the cecum, ascending and transverse colon are increasingly reported. Colorectal cancer most commonly metastasizes to the regional lymph nodes, liver, bone, lung, and brain. Rare metastases to mediastinal lymph nodes from colonic carcinomas have also been reported [2-5]. Postulated mechanisms of spread were lymphatic drainage routes of the liver in those with concurrent liver metastases; and paravertebral venous or paraaortic lymphatic plexus in those with concomitant pelvic or abdominal metastases. Mediastinal lymphadenopathy, attributed to coexisting sarcoidosis, has also been reported in one case of colon cancer [6]. To our knowledge, our report is the first in the literature to demonstrate solitary mediastinal lymph node metastases of colorectal carcinoma with no other site involvement. 


\section{Case Report}

We describe the case of a 67-year-old man with evidence of right paratracheal lymph node metastasis three years following the diagnosis of rectosigmoid carcinoma. In October 2004, the patient initially presented with symptoms and signs of intestinal obstruction. Computed tomography (CT) scan of the abdomen and pelvis showed diffuse circumferential intramural thickening with associated streaking of the adjacent fat planes in a short segment of the sigmoid colon. Sigmoidoscopic biopsy revealed an infiltrating moderately differentiated adenocarcinoma. Subtotal colectomy was eventually performed. Pathologic examination of the resected tissue revealed a five centimeter tumor invading the muscularis propria and pericolonic fat. Metastatic adenocarcinoma was noted in ten out of fifty peri-tumoral and mesenteric lymph nodes with extracapsular extension. The patient was eventually diagnosed with stage III adenocarcinoma of the rectosigmoid colon and given six cycles of adjuvant chemotherapy. In December 2006, a follow up total body CT scan identified an enlarged $1 \times 1 \mathrm{~cm}$ right paratracheal lymph node, with no evidence of pulmonary infiltrates, masses or fluid in the pleural cavities. There were no other significant findings in the pelvis or abdomen. The recommendation was to perform a fluor-18-deoxyglucose-positron emission tomography (18F-FDG PET) scan, which did not show any evidence of active disease; and hence, tumoral metastasis was ruled out and no action was taken. In October 2007, the previously identified lymph node appeared to have increased in size to approximately $2.2 \mathrm{~cm}$, with the remainder of the CT scan being insignificant. Mediastino-

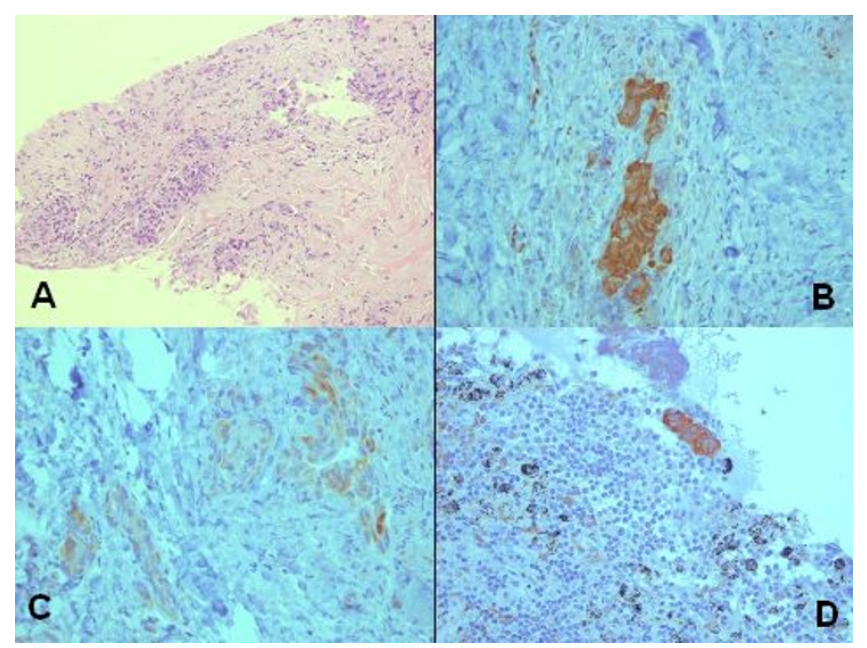

\section{Figure I}

Colonic tissue in paratracheal nodes. Paratracheal nodal involvement by metastatic adenocarcinoma (A) [H\&E, 200x]. The tumor cells are strongly positive for CK20 (B) [400x], weakly positive for CK7 (C) [400x]. Micrometastasis in another paratracheal lymph node (D) [400x]. scopic biopsy of the lymph node was done and revealed metastatic adenocarcinoma, similar to that of the colon (Figure $1 \mathrm{~A} ; \times 200$ ). Biopsy of another paratracheal lymph node showed two cell clusters of metastatic adenocarcinoma that were only identified by immunohistochemical analysis (Figure $1 \mathrm{~B} ; \times 400$ ). The metastatic tumor was positive for cytokeratin AE1/AE3 and cytokeratin 20 (Figure $1 \mathrm{C} ; \times 400$ ), weakly positive for cytokeratin 7 (Figure 1D; $\times 400$ ), and negative for thyroid transcription factor-1 (TTF1), confirming its colonic origin. Consequently, a total body ${ }^{18}$ F-FDG PET scan was requested which now identified the lymph node (Figure 2), and revealed no other significant findings. All through out the follow-up period the patient never had any respiratory or gastrointestinal symptoms. Ca19-9 and CEA serum levels were always within the normal range.

\section{Discussion}

We propose the following explanations for the incongruity between the follow-up imaging studies performed on the patient described in this report. ${ }^{18} \mathrm{~F}$-FDG PET scan has proven superior to morphologic imaging procedures when assessing lymph node involvement based on functional data evaluating tumor metabolism [7]. A metaanalysis of the most recent literature showed that changing the therapy plan by the use of 18 F-FDG PET scan in patients with colorectal metastatic cancer occurs in 31.6\% of the cases [8]. However, small malignant lesions may not show increased tracer uptake since current PET-detectors provide an in-plane spatial resolution of only 4-5 $\mathrm{mm}$. This limitation is most heightened in the thorax where lesion detection on PET is further compromised by respiratory motion (shallow breathing during PET acquisition) [9]. Furthermore, the extensive fibrosis evident by pathological examination of the mediastinal lymph node in our case might have led to a decrease in uptake of ${ }^{18} \mathrm{~F}-$ FDG during the initial PET scan in April 2006. Several studies, evaluating patients with different oncological diseases, have reported outstanding results concerning tumor staging when using PET/CT instead of separate morphological and functional data sets $[10,11]$.

Upgrading from stage III to stage IV ensues after detection of this distant metastasis. However, one question still

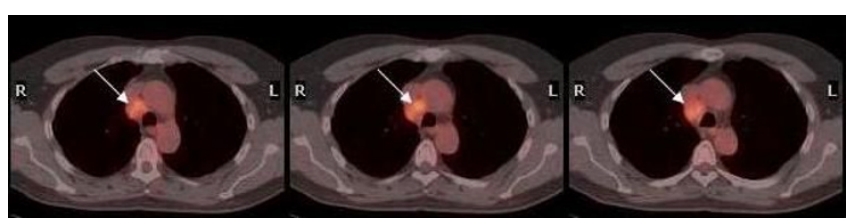

Figure 2

PET scan of thorax. ${ }^{18} \mathrm{~F}-\mathrm{FDG}$ PET scan of the thorax showing a $2.2 \mathrm{~cm}$ enlarged right paratracheal lymph node. 
remains: should the management of this patient rely on systemic chemotherapy only or could the patient benefit from loco-regional radiation and/or surgical resection? The rationale would be that resection or radiation of the mediastinal lymph node may prevent possibly fatal complications caused by tracheal and major vascular involvement; however, no evidence to support this reasoning currently exists.

\section{Conclusion}

Our case report suggests that attention should be paid to the mediastinum when evaluating PET scan or CT films during follow-up of patients with colorectal cancer. Moreover, despite the fact that the 18F-FDG PET scan has high specificity for colorectal metastases; all suspected lesions, identified though morphological imaging, must be further investigated if they can change the therapeutic plan. However, the choice between locoregional and chemotherapeutic subsequent management remains unclear in the case of solitary mediastinal metastasis.

\section{Consent}

Written informed consent was obtained from the patient for publication of this Case report and any accompanying images. A copy of the written consent is available for review by the Editor-in-Chief of this journal.

\section{Abbreviations}

18F-FDG PET: 18-F-fluorodeoxyglucose positron emission tomography; CT: Computed tomography; TTF1: Thyroid transcription factor- 1 .

\section{Competing interests}

The authors declare that they have no competing interests.

\section{Authors' contributions}

KMM designed the study, compiled the different sections of the report, and helped in writing the manuscript. AIS and ATT drafted the manuscript and revised it critically for important intellectual content. ANT, ZIC, and MZH helped in preparing the images and writing the pathology sections. All authors read and approved the final manuscript.

\section{References}

I. Jemal A, Siegel R, Ward E, Murray T, Xu J, Thun MJ: Cancer statistics, 2007. CA Cancer J Clin 2007, 57:43-66.

2. August DA, Sugarbaker PH, Schneider PD: Lymphatic dissemination of hepatic metastases: implications for the follow-up and treatment of patients with colorectal cancer. Cancer 1985, 55: I 490-I494.

3. Vetto JT, Cohen AM: Isolated spread of hepatic metastatic disease to a mediastinal lymph node: report of a case and review of pertinent anatomy and literature. Dis Colon Rectum 1991, 34: II28-II30.

4. Kuba H, Sato N, Uchiyama A, Nakafusa Y, Mibu R, Yoshida K, Kuroiwa KA 3, Tanaka M: Mediastinal lymph node metastasis of colon cancer: report of a case. Surg Today 1999, 29:375-377.
5. Tsubaki M, Nemoto K, Yoda N: Sigmoid colon cancer with mediastinal lymph node metastases. Int Surg 2007, 92:209-2I3.

6. Malani A, Gupta C, Singh J, Rangineni S: A 63-year-old woman with colon cancer and medisatinal lymphadenopathy. Chest 2007, I 3 I: 1970-1973.

7. Gambhir SS, Czernin J, Schwimmer J, Silverman DH, Coleman RE, Phelps ME: A tabulated summary of the FDG PET literature. J Nucl Med 200I, 42: IS-93S.

8. Wiering B, Krabbe PF, Jager GJ, Oyen WJ, Ruers TJ: The impact of fluor-18-deoxyglucose-positron emission tomography in the management of colorectal liver metastases. Cancer 2005, 104:2658-2670.

9. Veit P, Ruehm S, Kuehl H, Stergar H, Mueller S, Bockisch A, Antoch G: Lymph node staging with dual-modality PET/CT: Enhancing the diagnostic accuracy in oncology. Eur J Radiol 2006, 58:383-389.

10. Antoch G, Vogt FM, Freudenberg LS, Nazaradeh F, Goehde SC, Barkhausen J, Dahmen G, Bockisch A, Debatin JF, Ruehm SG: Whole-body dual modality PET/CT and whole-body MRI for tumor staging in oncology. JAMA 2003, 290:3199-3206.

II. Cohade C, Osman M, Leal J, Wahl RL: Direct comparison of (18) FFDG PET and PET/CT in patients with colorectal carcinoma. J Nucl Med 2003, 44: I797-I803.
Publish with Bio Med Central and every scientist can read your work free of charge

"BioMed Central will be the most significant development for disseminating the results of biomedical research in our lifetime. " Sir Paul Nurse, Cancer Research UK

Your research papers will be:

- available free of charge to the entire biomedical community

- peer reviewed and published immediately upon acceptance

- cited in PubMed and archived on PubMed Central

- yours - you keep the copyright

Submit your manuscript here:

http://www.biomedcentral.com/info/publishing_adv.asp
BioMedcentral 